\title{
Nd:YAG Capsulotomy Rates with Two Multifocal Intraocular Lenses
}

\author{
Huiran Bai $\mathbb{D}^{1,2}$ \\ Honglei Li $\mathbb{D}^{1,2}$ \\ Simeng Zheng ${ }^{1,2}$ \\ Lihong Sun ${ }^{1,2}$ \\ Xiaoming $\mathrm{Wu}^{1,2}$
}

'Qingdao Eye Hospital of Shandong First Medical University, Qingdao, People's

Republic of China; ${ }^{2}$ State Key Laboratory Cultivation Base, Shandong Provincial Key Laboratory of Ophthalmology, Shandong Eye Institute, Shandong First Medical University \& Shandong Academy of Medical Sciences, Qingdao, People's Republic of China
Correspondence: Xiaoming Wu Department of Ophthalmology, Qingdao Eye Hospital of Shandong First Medical University, Qingdao, 26607I, People's

Republic of China

Tel +86532-87610668

Email wuxiaominglmm@126.com
Purpose: To investigate the incidence of Nd:YAG capsulotomy after implantation of two types of multifocal intraocular lenses (MIOLs).

Methods: This retrospective analysis included patients who had undergone cataract extraction and implanted diffractive MIOL (Acri. LISA tri 839M) or asymmetric refractive MIOL (SBL-3) from May 2016 to September 2018. They were followed up for at least 3 years. During the followup period, the relevant data of patients were kept by special person in the hospital. The rates of $\mathrm{Nd}$ : YAG capsulotomy and the Kaplan-Meier survival curve were used to analyze the two groups.

Results: The Asymmetric Refractive MIOL group was comprised of 98 patients (121 eyes), while the Diffractive MIOL group was comprised of 99 patients (120 eyes). There were no significant differences in age, sex, or IOL power between the two groups. The Nd:YAG rate of the asymmetric refractive MIOL group and the diffractive MIOL group was $3.3 \%$ and $7.5 \%$ respectively $(\mathrm{P}=0.15)$ in the first year, $14.88 \%$ and $22.5 \%$ respectively $(\mathrm{P}=0.129)$ in the second year, and $21.49 \%$ and $34.17 \%$ respectively $(\mathrm{P}=0.028)$ in the third year. In the first 7 months of follow-up, the two groups showed the same performance in the Nd:YAG rate. After that, there was a difference between the two groups, and the difference gradually increased. Until the 27th month of follow-up, the difference was significant $(\mathrm{P}<0.05)$. What is more, there were significant differences in survival (without Nd:YAG capsulotomy)/failure (with Nd:YAG capsulotomy) functions ( $\mathrm{P}=0.0035)$.

Conclusion: The incidence of Nd:YAG laser capsulotomy in patients with diffractive MIOLs was higher than that in patients with asymmetric refractive MIOLs.

Keywords: Nd:YAG capsulotomy rates, asymmetric refractive MIOL, diffractive MIOL, posterior capsular opacification

\section{Introduction}

Multifocal intraocular lenses (MIOL) are correctional intraocular lenses that improve the visual range of patients. The lenses are also known as presbyopia correcting intraocular lenses. They have incomparable advantages over the monofocal intraocular lens. ${ }^{1}$ However, they have their unique complications because of the complexity of their design principle. Blurred vision is the biggest cause of dissatisfaction among patients with multifocal IOLs implantation. Blurred vision attributed to posterior capsule opacification (PCO) and postoperative residual ametropia are the major concerns. Herein, blurred vision and photic phenomena were attributed to PCO in $54 \%$ and $66 \%$ of examined eyes, respectively. PCO is a common complication after cataract extraction. It can disperse light into the eye, damage vision, and reduce visual quality. Although Nd:YAG laser posterior capsulotomy can be treated quickly and safely with only a few complications, there are still risks of macular edema, uveitis, intraocular lens injury, elevated intraocular 
pressure, and retinal detachment. ${ }^{2,3}$ Therefore, it is of great importance to reduce the incidence of PCO after IOL implantation. At present, there are various methods to prevent PCO, most of them are in the experimental stage. Besides the surgical measures taken during surgery, the material and design of the intraocular lens also affect the clinical application of multifocal intraocular lenses. Studies have reported that there are significant differences in Nd:YAG laser capsulotomy incidences caused by different designs and materials of intraocular lenses. ${ }^{4}$ In recent years, numerous new multifocal IOLs have emerged with the progress of technology. Surgeons need to know the rate of Nd:YAG laser capsulotomy of different intraocular lenses during the selection process.

This study aimed to investigate the rate of Nd:YAG laser capsulotomy after implantation of two types of multifocal IOLs (Table 1).

\section{Materials and Methods}

\section{Patient Characteristics}

This retrospective study was conducted in an ophthalmic hospital in China and accordance with Chinese law and the tenets of the revised Declaration of Helsinki. This study was approved by the Institutional Review Board of Qingdao Eye Hospital of Shandong First Medical

Table I Characteristics of the Two Types of Intraocular Lens

\begin{tabular}{|c|c|c|}
\hline Parameter & Diffractive MIOL & $\begin{array}{c}\text { Asymmetric } \\
\text { Refractive } \\
\text { MIOL }\end{array}$ \\
\hline $\begin{array}{l}\text { Intraocular } \\
\text { lens model }\end{array}$ & Acri LISA tri $839 \mathrm{M}$ & SBL-3 \\
\hline Material & $\begin{array}{l}\text { Hydrophilic acrylates with } \\
\text { hydrophobic surface }(25 \%)\end{array}$ & $\begin{array}{l}\text { Hydrophilic } \\
\text { acrylates }\end{array}$ \\
\hline $\begin{array}{l}\text { Optical } \\
\text { configuration }\end{array}$ & $\begin{array}{l}\text { Dihedral aspheric surface, } \\
\text { diffraction ring on anterior } \\
\text { surface }\end{array}$ & $\begin{array}{l}\text { Dihedral aspheric } \\
\text { surface }\end{array}$ \\
\hline $\begin{array}{l}\text { Optic } \\
\text { diameter }\end{array}$ & $6.0 \mathrm{~mm}$ & $5.75 \mathrm{~mm}$ \\
\hline $\begin{array}{l}\text { Overall } \\
\text { length }\end{array}$ & $11.0 \mathrm{~mm}$ & $11.0 \mathrm{~mm}$ \\
\hline Haptic & Tetragonal loop & Annular loop \\
\hline $\begin{array}{l}\text { Haptic } \\
\text { angulation }\end{array}$ & $0^{\circ}$ & $0^{\circ}$ \\
\hline IOL Design & $\begin{array}{c}\text { Optic and haptics with square } \\
\text { edges }\end{array}$ & $\begin{array}{l}\text { Optic and haptics } \\
\text { with square edges }\end{array}$ \\
\hline
\end{tabular}

University. Patients were informed of all the contents of this study and provided their written informed consent to participate before the study commenced.

Patients underwent surgery from May 2016 to September 2018 in Qingdao Eye Hospital of Shandong First Medical University. According to their desires, the two different multifocal IOLs were implanted into the eyes. The two types of MIOLs were introduced in the hospital at the same time. The patient's examination results were recorded and the relevant data as of September 20, 2021, were extracted. Patients with age-related cataracts and absence of medical eye history or physical examination findings considered to be contraindications for cataract surgery were included in the study. Nevertheless, patients with significant additional ophthalmic diseases such as pseudo-exfoliation and progressed retinal degenerations, preoperative astigmatism greater than 1.50 diopters, uncontrolled systemic diseases, and history of ocular surgery, uveitis, or trauma were excluded. In addition, patients with complications or loss of follow-up were also excluded.

\section{Surgical Procedure}

All surgeries were performed by one experienced surgeon with the Bausch \& Lomb Stellaris Vision Enhancement System using standard phacoemulsification techniques in both IOL groups. Temporal incisions that were $2.2 \mathrm{~mm}$ long were mostly made. In the same line, 5.5 to $6.0 \mathrm{~mm}$ capsulorhexis to overlap the entire optic of the IOL implant was created. All the patients were operated on successfully, and intraocular lenses were implanted into the capsule.

\section{Patient Evaluation}

When patients come for a follow-up visit, they had some postoperative examinations, including uncorrected distance visual acuity (UDVA), intraocular pressure, and slit-lamp examination. Nd:YAG laser capsulotomy was performed when two or more lines of UDVA were lost because of PCO or the patient complained of blurred vision and diplopia related to PCO.

\section{Data Analysis}

Data regarding patient characteristics, type of $\mathrm{IOL}$ implanted, Nd:YAG laser capsulotomy rates after IOL implantation, visual acuity before Nd:YAG laser capsulotomy, and time from surgery to Nd:YAG laser capsulotomy were collected.

Statistical analyses were performed using the Statistical Package for the Social Sciences software (version 22, SPSS, 
Inc). The Chi-square test was used to compare qualitative data while the non-parametric test was used for quantitative data. The independent $t$-test was used for normally distributed data, while the non-parametric Mann-Whitney test was for non-normally distributed data. The Kaplan-Meier survival curve was used for preliminary analysis using the eyes as the statistical unit. The Log rank test was used to test the equality of survival function between groups. $\mathrm{P}$ values less than $0.05(\mathrm{P}<0.05)$ indicated that there were significant differences between groups.

\section{Results}

The study included 241 eyes of 197 patients who underwent conventional phacoemulsification combined with intraocular lens implantation. Among them, 98 patients had been implanted with SBL-3 (Acri. Tec GmbH), while the remaining 99 patients had been implanted with Acri. LISA tri 839M (Carl Zeiss Meditec Co.). The 121 eyes formed the Asymmetric Refractive MIOL group while the 120 eyes formed the Diffractive MIOL group. The average age of 197 patients was $51.04 \pm 10.77$ years (range: 19-78 years). There were 135 males (68.53\%) in all the study population, including 73 in the Diffractive MIOL group and 62 in the Asymmetric Refractive MIOL group. During the follow-up period, 67 eyes $(27.80 \%)$ underwent Nd:YAG laser capsulotomy. The characteristics of patients and their eyes are summarized in Table 2.

The Nd:YAG rate of the Asymmetric Refractive MIOL group and the Diffractive MIOL group are compared in Table 3. There was no significant difference in the first and second years. With the extension of follow-up time, the rate of Nd:YAG laser capsulotomy of the two groups increased gradually, and the growth rate of the Diffractive MIOL group was faster, and the rate of $\mathrm{Nd}$ :YAG laser capsulotomy was higher. Until the 27th month of follow-up, the difference was significant $(\mathrm{P}=0.028)$. In the third year, the rate of $\mathrm{Nd}$ :YAG laser capsulotomy in the Diffractive MIOL group (34.17\%) was significantly higher than that in the Asymmetric Refraction MIOL group $(21.49 \%, \mathrm{P}<0.05)$, even though the material of diffractive multifocal IOL is hydrophilic acrylates with a hydrophobic surface. Before Nd:YAG laser capsulotomy, the UDVA $(0.45 \pm 0.27$ and $0.47 \pm 0.23$ LogMAR, respectively) of Diffractive MIOL and Asymmetric Refractive MIOL groups were no significant differences. The time between cataract surgery and Nd:YAG capsulotomy was shorter in the Diffractive MIOL group than in the Asymmetric Refraction MIOL, but was not clinically significant.

Figure 1 shows the proportion of patients that underwent Nd:YAG laser capsulotomy after IOL implantation. The survival analysis curves of Nd:YAG capsulotomy showed a similar trend for both groups in the first 7 months after the operation. Until the last follow-up, the Nd:YAG capsulotomy rate in the Diffractive MIOL group increased to $34.17 \%$. In contrast, the proportion of Nd:YAG capsulotomy in eyes with asymmetric refractive MIOL was only $21.49 \%$. The Log rank test for equality of survivor functions showed that there was a statistically significant difference between the two groups $(\mathrm{P}<0.05)$ (Figure 2).

\section{Discussion}

The purpose of this study was to investigate the rate of $\mathrm{Nd}$ : YAG laser capsulotomy in patients with diffractive MIOLs and asymmetric refractive MIOLs of different materials and designs. In this study, the results showed that there was no difference in the incidence of Nd:YAG laser capsulotomy between two groups in the first 2 years, and in the third year, the incidence of Nd:YAG laser capsulotomy of diffractive MIOLs was significantly higher than that of asymmetric refractive MIOLs. In addition, the Diffractive MIOL group increased faster.

Table 2 Demographics and Baseline Characteristics

\begin{tabular}{|c|c|c|c|c|c|c|c|c|c|}
\hline \multirow[t]{2}{*}{ Variable } & \multicolumn{4}{|c|}{ Diffractive MIOL } & \multicolumn{4}{|c|}{ Asymmetric Refractive MIOL } & \multirow[t]{2}{*}{$\mathbf{P}$} \\
\hline & No. & $\begin{array}{c}\text { Range } \\
\text { (Min/Max) }\end{array}$ & Mean \pm SD & $\begin{array}{c}\text { Median } \\
(\text { Q25/Q75) }\end{array}$ & No. & $\begin{array}{c}\text { Range } \\
\text { (Min/Max) }\end{array}$ & Mean \pm SD & $\begin{array}{c}\text { Median } \\
\text { (Q25/Q75) }\end{array}$ & \\
\hline Age, y & 99 & 19/7| & $50 \pm 12$ & $50(4 I / 56)$ & 98 & $22 / 64$ & $53 \pm 9$ & $53(47 / 60)$ & $0.06^{*}$ \\
\hline Lens power(D) & 120 & $7 / 25$ & $17.64 \pm 4.4$ & $19(13.0 / 20.5)$ & 121 & $10 / 24$ & $19.04 \pm 2.93$ & 19.0(I7.0/20.5) & $0.056^{\#}$ \\
\hline Male/Female(n)\% & \multicolumn{4}{|c|}{$73 / 26(73.7 \% / 26.3 \%)$} & \multicolumn{4}{|c|}{$62 / 36(63.3 \% / 36.7 \%)$} & $0.1^{+}$ \\
\hline
\end{tabular}

Notes: "Data non-normally distributed. Non-parametric Mann-Whitney test used. *Independent $t$-test. + chi-square test.

Abbreviation: SD, standard deviation. 
Table 3 Comparison of Nd:YAG Capsulotomy Rates Between the Two Groups

\begin{tabular}{|c|c|c|c|}
\hline Variable & $\begin{array}{l}\text { Diffractive } \\
\text { MIOL }\end{array}$ & $\begin{array}{c}\text { Asymmetric } \\
\text { Refractive } \\
\text { MIOL }\end{array}$ & $\mathbf{P}$ \\
\hline $\begin{array}{l}\text { Months from } \\
\text { surgery to Nd:YAG } \\
\text { (Mean } \pm \mathrm{SD} \text { ) }\end{array}$ & $20.21 \pm 9.47$ & $22.11 \pm 10.46$ & $0.36 *$ \\
\hline $\begin{array}{l}\text { UDVA before Nd: } \\
\text { YAG (Mean } \pm S D)\end{array}$ & $0.45 \pm 0.27$ & $0.47 \pm 0.23$ & $0.8 I^{*}$ \\
\hline \multicolumn{4}{|l|}{ Nd:YAG rate (\%) } \\
\hline$\leq 1$ year & $9 / 120$ (7.5\%) & 4/12I (3.3\%) & $0.15^{+}$ \\
\hline$\leq 2$ year & $27 / 120$ (22.5\%) & I8/I2I (I4.88\%) & $0.129^{+}$ \\
\hline$\leq 3$ year & $4 \mathrm{I} / 120(34.17 \%)$ & $26 / 12 \mid$ (2I.49\%) & $0.028^{+}$ \\
\hline
\end{tabular}

Notes: *Independent $t$-test. + chi-square test.

Abbreviations: MIOL, multifocal intraocular lens; UDVA, uncorrected distance visual acuity.

PCO is one of the most common long-term complications associated with cataract extraction. ${ }^{5}$ The formation process of PCO is influenced by many factors and can be affected by the patient's age, disease status, surgical technique, as well as the design and materials of the intraocular lenses. ${ }^{6,7}$ Schmidbauer et al, 2002 reported that surgical and IOL-related factors were the main factors affecting the occurrence of $\mathrm{PCO}^{8}$ In this study, all surgeries were performed by an experienced surgeon in the same way, so we think surgical factors were not significantly different between the two groups. The main difference were IOL-related factors, including the material and design of the intraocular lenses.

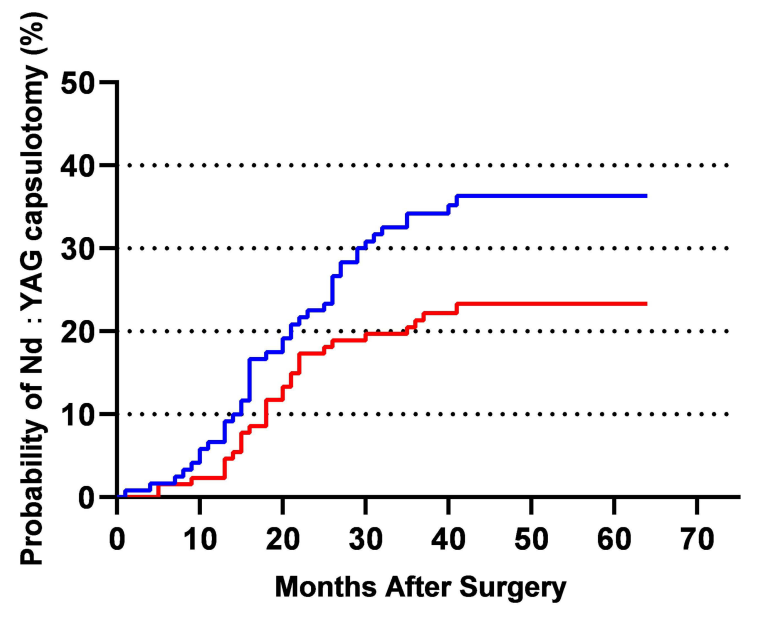

Diffractive MIOL — Asymmetric Refractive MIOL

Figure I The probability of having Nd:YAG capsulotomy up to the time point $\mathrm{t}$.

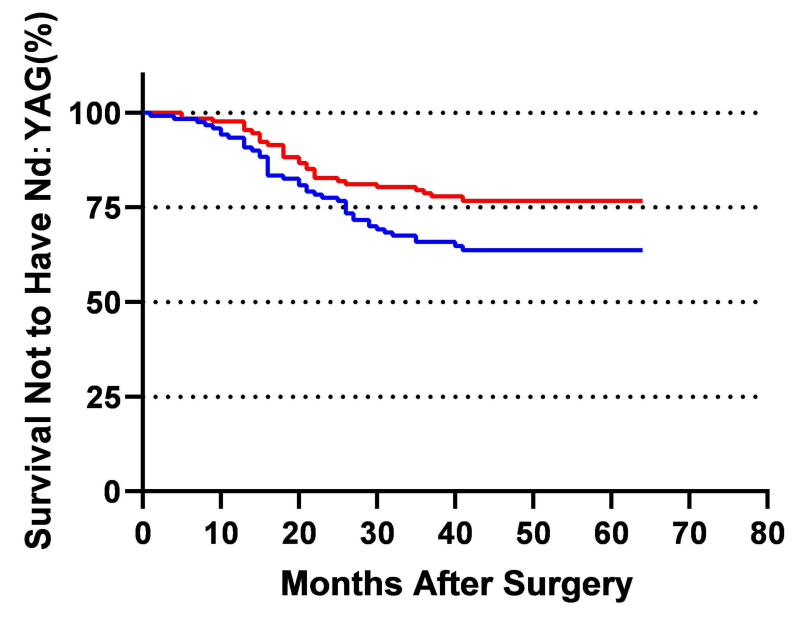

Diffractive MIOL

Asymmetric Refractive MIOL

Figure 2 The probability of not having Nd:YAG capsulotomy up to the time point t. Log rank test for equality of survivor functions $(P<0.05)$.

A real-world evidence study in the UK reported that the 3-year incidence of Nd:YAG laser capsulotomy in eyes with hydrophilic acrylic monofocal intraocular lens was $10.9 \%{ }^{9}$ In our study, the incidence of Nd:YAG laser capsulotomy was $27.80 \%$, which was much higher than the real-world evidence study. However, previous studies have shown that patients with MIOLs are more sensitive to PCO when compared to patients with monofocal IOLs. ${ }^{10-13}$ The reason may be that patients with MIOLs have a higher demand for visual function, and the contrast sensitivity and visual quality of multifocal IOLs are lower than those of monofocal IOLs. In addition, Javaloy et al, 2019 reported that the $\mathrm{Nd}$ : YAG capsulotomy rate of Acri LISA tri 839M was 27.31\% in the 2-year follow-up period, ${ }^{14}$ Bilbao-Calabuig et al, 2016 reported the Nd:YAG capsulotomy rate after Acri LISA tri $839 \mathrm{M}$ implantation of $35 \%$ in 3 years. ${ }^{15}$ In this study, the Nd:YAG capsulotomy rate of Acri LISA tri $839 \mathrm{M}$ was $22.5 \%$ and $34.17 \%$ respectively in the second and third years. The result was in agreement with the previous study. As far as we know, there is no relevant data about the $\mathrm{Nd}$ : YAG capsulotomy rate of hydrophilic asymmetric refractive MIOL, this study is the first report. In our study, the Nd: YAG capsulotomy rate of SBL-3 was 3.3\%, $14.88 \%$ and $21.49 \%$ respectively in the first, second, and third year.

In previous studies about Nd:YAG capsulotomy rates evaluation showed hydrophilic lenses had statistically higher Nd:YAG capsulotomy rates than hydrophobic lenses. ${ }^{4,16,17}$ In this study, although there are slight differences in the design of the two kinds of multifocal IOLs, their optical configurations are dihedral aspheric surface with square 
edges, the multifocal design is located on the front surface, the back surface is aspheric, and the haptic angulation is $0^{\circ}$. In terms of materials, both are hydrophilic multifocal IOLs, but diffractive MIOL has a hydrophobic surface. As it is known the incidence of PCO in hydrophobic IOL is much lower than that in hydrophilic IOL. The diffractive MIOL in this study has a hydrophobic surface, which should have better performance in inhibiting PCO in theory. However, this advantage was not shown in our study.

The previous research reports said that the tolerance of diffractive MIOL to PCO is lower than that of monofocal IOL. Diffractive MIOL is also easily affected by PCO. ${ }^{15,18}$ Though the PCO or posterior capsular wrinkle has no effect on monofocal IOL eyes, it can reduce the visual quality of MIOL eyes and cause blurred vision. Elgohary et al, 2008 reported that PCO has a comparable effect on visual function in both monofocal and multifocal IOL. ${ }^{19}$ However, patients with MIOL received Nd:YAG capsulotomy earlier. Moreover, their degree of visual dysfunction was less. In this study, there was no significant difference in visual acuity between the two groups before Nd:YAG laser capsulotomy, this strongly suggested that they have the same tolerance to PCO.

Therefore, the hypothesis why Nd:YAG laser capsulotomy is performed more frequently in eyes with diffractive MIOLs than in eyes with asymmetric refractive MIOLs is that the latter has less light loss and higher contrast sensitivity. The most significant difference between the two types of multifocal IOLs was the different ways of light splitting. Asymmetric refractive MIOL divides light through two optical parts with different refractive power, diffractive MIOL divides light through a diffraction ring. In previous studies on the visual quality of diffractive MIOL and refractive MIOL, the light loss of refractive MIOL was less and the photopic contrast sensitivity was better. ${ }^{20}$ The total light loss of asymmetric refractive MIOL is about $7 \%$, which of diffractive MIOL is $17 \%$. Therefore, we speculate that less light loss and higher contrast sensitivity may be the main reasons for the results of this study.

There are some limitations of this study that should be considered. First, the study was retrospective, with a small sample. Second, we compare the incidence of $\mathrm{Nd}: \mathrm{YAG}$ laser capsulotomy, but the grade of PCO did not be assessed. However, it may be a good index of visual loss caused by PCO after implantation of IOLs. Third, Without interocular correlation being considered, the binocular data of a small number of patients were included in this study.
In the future, a large sample size study should be conducted to confirm that the incidence of PCO of different types of multifocal IOLs with the same material.

\section{Conclusion}

During the 3-year follow-up period, the incidence of Nd: YAG laser capsulotomy of the two groups increased gradually, but the Diffractive MIOL group increased faster. The rate of Nd:YAG capsulotomy of the Asymmetric Refractive MIOL group was significantly less than the Diffractive MIOL group. Although the diffractive multifocal intraocular lens has a hydrophobic surface, which can inhibit PCO, this advantage was not shown when compared with the asymmetric refractive multifocal intraocular lens in this study.

\section{Ethics Approval and Consent to Participate}

The study was conducted under the Declaration of Helsinki. This study was approved by the Ethics Committee of Qingdao Eye Hospital of Shandong First Medical University. Informed consent was obtained from each participant.

\section{Acknowledgment}

The authors are grateful to all participants for their voluntary participation. In addition, thanks to Xiujing Shi for analyzing some data and his comments on the manuscript.

\section{Funding}

There is no funding to report.

\section{Disclosure}

All authors report no conflicts of interest relevant to this article.

\section{References}

1. Alio JL, Plaza-Puche AB, Fernandez-Buenaga R, Pikkeland J, Maldonado M. Multifocal intraocular lenses: an overview. Surv Ophthalmol. 2017;62(5):611-634. doi:10.1016/j.survophthal.20 17.03.005

2. Kossack N, Schindler C, Weinhold I, et al. German claims data analysis to assess impact of different intraocular lenses on posterior capsule opacification and related healthcare costs. Z Gesundh Wiss. 2018;26(1):81-90. doi:10.1007/s10389-017-0851-y

3. Wesolosky JD, Tennantand M, Rudnisky CJ. Rate of retinal tear and detachment after neodymium: YAG capsulotomy. J Cataract Refract Surg. 2017;43(7):923-928. doi:10.1016/j.jcrs.2017.03.046

4. Iliescu IM, Constantin MA, Cozma C, Moraruand OM, Moraru CM. Posterior capsule opacification and Nd-YAG rates evaluation in a large series of pseudophakic cases. Rom J Ophthalmol. 2017;61(4):267-274. doi:10.22336/rjo.2017.48 
5. Findl O, Buehl W, Bauerand P, Sycha T. Interventions for preventing posterior capsule opacification. Cochrane Database Syst Rev. 2010;2: CD003738.

6. Coombesand A, Seward H. Posterior capsular opacification prevention: IOL design and material. $\mathrm{Br} J$ Ophthalmol. 1999;83 (6):640-641. doi:10.1136/bjo.83.6.640

7. Hecht I, Karesvuo P, Achiron A, Elbaz U, Laineand I, Tuuminen R. Anti-inflammatory medication after cataract surgery and posterior capsular opacification. Am J Ophthalmol. 2020;215:104-111. doi:10.1016/j.ajo.2020.02.007

8. Schmidbauer JM, Escobar-Gomez M, Apple DJ, Peng Q, Arthurand SN, Vargas LG. Effect of haptic angulation on posterior capsule opacification in modern foldable lenses with a square, truncated optic edge. J Cataract Refract Surg. 2002;28(7):1251-1255. doi:10.1016/S0886-3350(02)01214-2

9. Ursell PG, Dhariwal M, Majirska K, et al. Three-year incidence of Nd:YAG capsulotomy and posterior capsule opacification and its relationship to monofocal acrylic IOL biomaterial: a UK Real World Evidence study. Eye. 2018;32(10):1579-1589. doi:10.1038/ s41433-018-0131-2

10. McNeely RN, Pazo E, Spence A, et al. Visual quality and performance comparison between 2 refractive rotationally asymmetric multifocal intraocular lenses. J Cataract Refract Surg. 2017;43 (8):1020-1026. doi:10.1016/j.jcrs.2017.05.039

11. Ouchi M. Primary posterior continuous curvilinear capsulorhexis combined with diffractive multifocal intraocular lens implantation. Eye. 2016;30(1):95-101. doi:10.1038/eye.2015.201

12. Kamiya K, Hayashi K, Shimizu K, Negishi K, Sato M, BissenMiyajima H; Survey Working Group of the Japanese Society ofand S. Refractive. Multifocal intraocular lens explantation: a case series of 50 eyes. Am J Ophthalmol. 2014;158(2):215-220 e211. doi:10.1016/j.ajo.2014.04.010

13. Kim JW, Eom Y, Yoon EG, et al. Comparison of Nd:YAG laser capsulotomy rates between refractive segmented multifocal and multifocal toric intraocular lenses. Am J Ophthalmol. 2021;222 (2):359-367. doi:10.1016/j.ajo.2020.09.046
14. Javaloy J, Rivera E, Montalban R, Beltran J, Munozand G, Rohrweck S. Diffractive trifocal pseudophakic intraocular lenses in high myopic eyes: 2-year assessment after implantation. Graefes Arch Clin Exp Ophthalmol. 2019;257(6):1331-1339. doi:10.1007/ s00417-019-04302-5

15. Bilbao-Calabuig R, Llovet-Osuna F, Gonzalez-Lopezand F, Beltran J. Nd:YAG capsulotomy rates with two trifocal intraocular lenses. $J$ Refract Surg. 2016;32(11):748-752. doi:10.3928/1081597X20160803-02

16. Joshi RS. Postoperative posterior capsular striae and the posterior capsular opacification in patients implanted with two types of intraocular lens material. Indian J Ophthalmol. 2017;65(6):466-471. doi:10.4103/ijo.IJO_344_16

17. Gauthier L, Lafuma A, Laurendeauand C, Berdeaux G. Neodymium: YAGlaser rates after bilateral implantation of hydrophobic or hydrophilic multifocal intraocular lenses: twenty-four month retrospective comparative study. J Cataract Refract Surg. 2010;36(7):1195-1200. doi:10.1016/j.jcrs.2010.01.027

18. Zhao Y, Yang K, Li J, Huang. Y, Zhu S. Comparison of hydrophobic and hydrophilic intraocular lens in preventing posterior capsule opacification after cataract surgery: an updated meta-analysis. Medicine. 2017;96(44):e8301. doi:10.1097/MD.0000000000008301

19. Elgoharyand MA, Beckingsale AB. Effect of posterior capsular opacification on visual function in patients with monofocal and multifocal intraocular lenses. Eye. 2008;22(5):613-619. doi:10.1038/sj. eye.6702661

20. Alio JL, Plaza-Puche AB, Javaloyand J, Ayala MJ. Comparison of the visual and intraocular optical performance of a refractive multifocal IOL with rotational asymmetry and an apodized diffractive multifocal IOL. J Refract Surg. 2012;28(2):100-105. doi:10.3928/ 1081597X-20120110-01
International Journal of General Medicine

\section{Publish your work in this journal}

The International Journal of General Medicine is an international, peer-reviewed open-access journal that focuses on general and internal medicine, pathogenesis, epidemiology, diagnosis, monitoring and treatment protocols. The journal is characterized by the rapid reporting of reviews, original research and clinical studies

\section{Dovepress}

across all disease areas. The manuscript management system is completely online and includes a very quick and fair peer-review system, which is all easy to use. Visit http://www.dovepress.com/ testimonials.php to read real quotes from published authors. 